\title{
DEA based estimation of the technical efficiency of state transport undertakings in India
}

\author{
Shivi Agarwal • Shiv Prasad Yadav • S. P. Singh
}

Accepted: 29 May 2009 /Published online: 1 February 2011

(C) Operational Research Society of India 2011

\begin{abstract}
This paper measures the technical efficiency of public transport sector in India. The study makes an attempt to provide an overview of the general status of the State Transport Undertakings (STUs) in terms of their productive efficiency. Data have been collected for 35 STUs for the year 2004-2005. Technical efficiency of the STUs is measured by applying Data Envelopment Analysis (DEA) technique with the use of four input and three output variables. Fleet size, Total staff, Fuel consumption and Accident per lakh kilometer are considered as inputs and Bus utilization, Passenger kilometers and Load factor as outputs. On the basis of the status of technical efficiency, it is concluded that the performance of the STUs are good but still very far from the optimal level. The mean overall technical efficiency (OTE) is $83.26 \%$ which indicates that an average STU has the scope of producing the same output with the inputs $16.74 \%$ lesser than their existing level. Significant variation in OTE across STUs is also observed.
\end{abstract}

Keywords DEA Efficiency·Transport

\section{Introduction}

Transport sector plays a significant role in the overall development of a nation's economy. Road transport is the prime motorized mode of transport linking the remote and hilly areas with rest of the country. The State Transport Undertakings

\footnotetext{
S. Agarwal

Department of Mathematics, BITS, Pilani -333031, India

e-mail: shividma@gmail.com

S. P. Yadav $(\bowtie)$

Department of Mathematics, IIT, Roorkee 247667, India

e-mail: yadavfma@iitr.ernet.in

S. P. Singh

Department of Humanities and Social Sciences, IIT, Roorkee 247667, India

e-mail: singhfhs@iitr.ernet.in
} 
(STUs), controlled by the respective state government, are the imperative mode of passenger mobility in public road transport sector.

Since STUs are public utility service with a social objective, it is essential to regularly monitor their performance, specifically with a view to identifying appropriate measures including proper investment and pricing policy and to improve their output efficiency. In public transport sector, efficiency measurement is the first step in the evaluation of individual performance of STUs. This study is an attempt in this direction to assess the relative technical efficiency of STUs in India.

Passenger road transportation is a "service business" and evaluating the efficiency of a service business is a complex matter. Transport efficiency is often more difficult to evaluate than manufacturing business efficiency, because it is difficult to determine the efficient amount of resources required to produce various service outputs. The manufacturing standard can be used to identify operating inefficiencies through classical cost accounting variance analyses. However, in service organization like road passenger transportation system, it is difficult to identify the specific resources required to provide a specific service output.

The purpose of this article is to evaluate the performance of STUs by providing them with a mathematical technique to analyse the efficiency with which service is rendered. The paper attempts to estimate technical efficiency of the STUs, sets benchmark for inefficient STUs, and suggests alternative actions that would make them relatively efficient. The paper is organized as follows: in Section 2 methodology is given. Empirical Results and discussions are given in Section 3, followed by conclusions in the last.

\section{Methodology}

This paper measures the technical efficiencies of the STUs. The technical efficiency refers to the extent to which a STU can produce maximum output from its chosen combination of factor inputs.

The mathematical relationship between inputs and outputs in transport sector is not known clearly, so STU efficiency is operationalized using Data Envelopment Analysis (DEA). It is a non-parametric linear programming model that estimates the magnitude of departure from efficiency frontiers for each STU. The DEA model is used to measure the OTE. The DEA is initially proposed by Charnes, Cooper and Rhodes [2]. DEA measures the relative technical efficiency of a group of decisionmaking units (DMUs) by simultaneously evaluating multiple inputs and outputs common to each unit; each DMU is thus assigned an efficiency score. The DEA model is a family of fractional linear programs; each linear program measures the relative efficiency of a particular DMU. Even though the modeling is nonlinear but under appropriate transformations the efficiency rating can be derived from an equivalent linear program (Charnes and Cooper [4]).

DEA is chosen over other methods because

$\triangleright$ It handles multiple inputs and multiple outputs;

$\gg$ It does not require a prior weights (as in index numbers);

$\triangleright$ It emphasizes individual observations rather than statistical estimates (as in regression analysis); 
$\triangleright$ It is a dynamic analytical decision-making tool that not only provides a "snapshot" of the current efficiency of the DMU compared with the group, but also indicates possibilities for improving relative efficiency;

$\triangleright$ It uses benchmarking approach to measure STU efficiency relative to others in their group.

$\triangleright$ It can assist in identifying best-practice or efficient STUs and inefficient STUs within the group.

$\triangleright$ The DEA results can allow policy makers to develop policies that can assist the relatively inefficient STUs to improve their performance.

\subsection{Algorithm}

First Step: Selection of the Homogeneous DMUs

We measure the OTE of 35 STUs using data from CIRT [5] for the year 2004-05. A list of these 35 selected STUs is given in the Appendix A.1.

Second Step: Selection of Input and Output Variables

To evaluate the relative efficiency of the STUs, four inputs, viz., Fleet size (FS), Total Staff (TS), Fuel consumption (FC) and Accident per lakh kilometers (APLK) and three outputs, namely, Bus Utilisation (BU), Passenger kilometers (Pass-Kms) and Load Factor (LF) are considered.

\subsection{Inputs}

1. Fleet Size (number of buses in hundred) comprises the average number of buses on-road in a STU; it is representative of the capital input.

2. Total Staff (numbers in thousand) refers to the total number of employees worked in a STU; it is representative of the labour input.

3. Fuel Consumption refers to the fuel consumed (in ten thousand kilolitres) which is measured by dividing total earned kilometer by fuel average; it is representative of the material input.

4. Accident per lakh kilometers is important parameter of safety in bus operation.

\subsection{Outputs}

1. Bus Utilisation (in kilometers) is defined as kilometers done per bus on road per day. It is calculated from dividing total effective kilometers done on a day by total buses on road on that day.

2. Passenger-kilometers (in Billions) is a measure of service utilization which represents the cumulative sum of the distances ridden by each passenger. It is normally calculated by summation of the passenger load times the distance between individual bus stops.

3. Load Factor is the percent of the ratio of passengers actually carried versus the total passenger seating capacity.

The details of the observed data for the selected STUs of the input and output variables are shown in Table 1 . There is a perceptible variation in the inputs and the 
Table 1 Observed data of the sample STUs in India (2004-05)

\begin{tabular}{|c|c|c|c|c|c|c|c|c|}
\hline \multirow[t]{2}{*}{ Sr. No } & \multirow[t]{2}{*}{ STU name } & \multicolumn{4}{|l|}{ Inputs } & \multicolumn{3}{|l|}{ Outputs } \\
\hline & & $\begin{array}{l}\text { FS (No. in } \\
\text { hundred }\end{array}$ & $\begin{array}{l}\text { TS (No. in } \\
\text { thousand) }\end{array}$ & $\begin{array}{l}\mathrm{FC} \text { (in ten } \\
\text { thousand } \\
\text { kilolitres) }\end{array}$ & $\begin{array}{l}\text { APLK } \\
\text { (No.) }\end{array}$ & BU (\%) & $\begin{array}{l}\text { Pass Kms } \\
\text { (No. in Billion) }\end{array}$ & LF (\%) \\
\hline S1 & APSRTC & 191.05 & 117.4 & 43.951 & 0.1 & 333.4 & 762.554 & 62 \\
\hline S2 & MSRTC & 152.29 & 102.231 & 37.373 & 0.18 & 323.4 & 514.126 & 45 \\
\hline S3 & GSRTC & 71.13 & 52.043 & 17.825 & 0.15 & 356.3 & 272.587 & 57.6 \\
\hline S4 & UPSRTC & 64.48 & 39.757 & 14.431 & 0.13 & 308.4 & 234.704 & 62.2 \\
\hline S5 & RSRTC & 44.09 & 22.651 & 11.148 & 0.12 & 346.4 & 203.756 & 70.3 \\
\hline S6 & KnSRTC & 43.47 & 24.989 & 11.003 & 0.16 & 366.2 & 225.627 & 69.6 \\
\hline S7 & NWKnSRTC & 31.51 & 20.527 & 8.466 & 0.13 & 394.6 & 174.015 & 63.9 \\
\hline S8 & NSKnSRTC & 23.7 & 10.073 & 4.859 & 0.09 & 305.6 & 100.05 & 74.2 \\
\hline S9 & STHAR & 31.41 & 18.354 & 8.435 & 0.08 & 359.1 & 146.63 & 68.5 \\
\hline S10 & STPJB & 14.44 & 9.5 & 3.000 & 0.07 & 244.8 & 40.254 & 60 \\
\hline S11 & BSRTC & 4.95 & 4.873 & 0.997 & 0.01 & 216.3 & 12.611 & 67.2 \\
\hline $\mathrm{S} 12$ & $\mathrm{CBE}$ & 23.52 & 15.91 & 7.608 & 0.32 & 405.9 & 168.517 & 72.5 \\
\hline $\mathrm{S} 13$ & KUM-1 & 5.55 & 3.758 & 1.905 & 0.25 & 469.2 & 43.018 & 71.1 \\
\hline S14 & KUM-2 & 8.36 & 5.707 & 2.820 & 0.32 & 440.8 & 61.732 & 72.6 \\
\hline S15 & MDU & 32.94 & 22.198 & 10.643 & 0.32 & 427.5 & 234.234 & 69 \\
\hline S16 & SLM & 15.41 & 10.687 & 5.233 & 0.19 & 447.5 & 120.124 & 71 \\
\hline S17 & VPM-1 & 10.39 & 7.222 & 4.012 & 0.29 & 485.6 & 105.375 & 82.8 \\
\hline $\mathrm{S} 18$ & VPM-3 & 7.42 & 5.433 & 2.518 & 0.24 & 440.7 & 55.911 & 73.5 \\
\hline S19 & $\mathrm{TN}$ & 8.2 & 6.971 & 3.973 & 0.31 & 621.3 & 61.932 & 78.5 \\
\hline S20 & NBSTC & 4.23 & 5.576 & 0.992 & 0.23 & 243.4 & 12.806 & 68.1 \\
\hline S21 & SBSTC & 3.26 & 2.825 & 0.887 & 0.2 & 305 & 9.907 & 54.6 \\
\hline S22 & KDTC & 3.27 & 1.983 & 0.669 & 0.37 & 258.2 & 9.644 & 53.4 \\
\hline S23 & OSRTC & 2.28 & 1.336 & 0.584 & 0.04 & 307.4 & 8.296 & 69 \\
\hline S24 & HRTC & 16.64 & 8.711 & 3.838 & 0.1 & 230 & 40.104 & 49.5 \\
\hline S25 & TRPTC & 0.61 & 0.72 & 0.081 & 0.03 & 130 & 1.01 & 71.8 \\
\hline S26 & MZST & 0.28 & 0.831 & 0.045 & 0.001 & 126.5 & 0.185 & 38.9 \\
\hline S27 & BEST & 30.71 & 35.785 & 7.508 & 0.34 & 213.7 & 106.961 & 60.5 \\
\hline S28 & DTC & 30.1 & 29.2 & 8.082 & 0.16 & 229.6 & 108.193 & 63.8 \\
\hline S29 & $\mathrm{CNI}$ & 21.87 & 18.523 & 5.712 & 0.52 & 261.2 & 122.995 & 80.8 \\
\hline S30 & BMTC & 35.34 & 17.759 & 6.273 & 0.19 & 230.5 & 124.822 & 77.2 \\
\hline S31 & CSTC & 7.07 & 7.741 & 1.513 & 0.2 & 216.9 & 19.496 & 86.8 \\
\hline S32 & AMTS & 3.71 & 3.986 & 0.814 & 0.75 & 208.7 & 10.325 & 54.7 \\
\hline S33 & PCMT & 1.23 & 1.895 & 0.327 & 0.49 & 265.7 & 4.093 & 73 \\
\hline S34 & KMTU & 1.28 & 0.78 & 0.301 & 1.11 & 237.7 & 4.567 & 79.4 \\
\hline S35 & PMT & 7.64 & 6.913 & 1.797 & 0.37 & 212 & 22.748 & 62 \\
\hline Mean & & 27.25 & 18.42 & 6.85 & 0.24 & 313.41 & 118.40 & 66.71 \\
\hline
\end{tabular}

Available on www.asrtu.org \scan0012.pdf accessed on 15 March 2006 
outputs across STUs. All the inputs used are in some cases hundred times larger than that used by other STU. The variations in outputs produced are not so high except Pass-Kms.

Third Step: Fourth Step: Selection of the model

In this study, CCR input-oriented model has been employed, i.e., how much resources can be reduced without changing the outputs produced to make STUs efficient (Charnes et al. [4]). In order to decompose the overall technical efficiency (OTE) into pure technical efficiency (PTE) and scale efficiency (SE), BCC input-oriented model is also applied to the data. Descriptive statistics of the results are given in Tables 2 and 5 .

Fourth Step: Calculating the overall technical efficiency (OTE) of STU

To describe DEA efficiency evaluation, assume that the performance of the homogeneous set of $\mathrm{n}$ decision making units $\left(\mathrm{DMU}_{j} ; j=1 \ldots \mathrm{n}\right)$ be measured by DEA. The performance of $\mathrm{DMU}_{j}$ is characterized by a production process of $\mathrm{m}$ inputs $\left(\mathrm{x}_{i j} ; i=1 \ldots \mathrm{m}\right)$ to yield $\mathrm{s}$ outputs $\left(\mathrm{y}_{r j} ; r=1 \ldots \mathrm{s}\right)$. According to Charnes et al. [2], the ratio of the virtual output to the virtual input of any $\mathrm{DMU}_{k}$ is to be maximized with the condition that the ratio of virtual output to virtual input of every DMU should be less than or equal to unity.

Mathematically,

$$
\operatorname{Max}_{k}=\frac{\sum_{r=1}^{s} u_{r k} y_{r k}}{\sum_{i=1}^{m} v_{i k} x_{i k}}
$$

subject to

$$
\begin{aligned}
& \frac{\sum_{r=1}^{s} u_{r k} y_{r j}}{\sum_{i=1}^{m} v_{i k} x_{i j}} \leq 1 \quad \forall \mathrm{j}=1,2, \ldots, \mathrm{n} \\
& \frac{u_{r k}}{\sum_{i=1}^{m} v_{i k} x_{i k}} \geq \varepsilon \quad \forall \mathrm{r}=1,2, \ldots, \mathrm{s} \\
& \frac{v_{i k}}{\sum_{i=1}^{m} v_{i k} x_{i k}} \geq \varepsilon \quad \forall \mathrm{i}=1,2, \ldots, \mathrm{m}
\end{aligned}
$$

where $\mathrm{y}_{r k}$ is the amount of the $\mathrm{r}^{\text {th }}$ output produced by the $\mathrm{k}^{\text {th }} \mathrm{DMU} ; \mathrm{x}_{i k}$ is the amount of the $\mathrm{i}^{\text {th }}$ input used by the $\mathrm{k}^{\text {th }} \mathrm{DMU} ; \mathrm{u}_{r k}$ is the weight given to the $\mathrm{r}^{\text {th }}$ output of the $\mathrm{k}^{\text {th }} \mathrm{DMU} ; \mathrm{v}_{i k}$ is the weight given to the $\mathrm{i}^{\text {th }}$ input of the $\mathrm{k}^{\text {th }} \mathrm{DMU}$; $\mathrm{n}$ is the no. of DMUs; $\mathrm{s}$ is the no. of outputs; $\mathrm{m}$ is the no. of inputs and $\varepsilon$ is a non-Archimedean (infinitesimal) constant.

The model (1) is popularly known as the classical CCR ratio model named after Charnes, Cooper and Rhodes. The theory of fractional linear programming 
Table 2 Resulting efficiency scores of STUs by DEA model

\begin{tabular}{|c|c|c|c|c|}
\hline STU No. & Efficiency scores & Reference set & Peer weight & Peer count \\
\hline $\mathrm{S} 1$ & 1.00 & $\mathrm{~S} 1$ & 1.00 & 4 \\
\hline $\mathrm{S} 2$ & 0.790 & $\mathrm{~S} 1, \mathrm{~S} 7$ & $0.51,0.70$ & 0 \\
\hline $\mathrm{S} 3$ & 0.821 & $\mathrm{~S} 1, \mathrm{~S} 7$ & $0.17,0.82$ & 0 \\
\hline S4 & 0.853 & $\mathrm{~S} 1, \mathrm{~S} 6, \mathrm{~S} 26$ & $0.13,0.61,0.33$ & 0 \\
\hline S5 & 1.00 & S5 & 1.00 & 0 \\
\hline S6 & 1.00 & S6 & 1.00 & 5 \\
\hline S7 & 1.00 & S7 & 1.00 & 3 \\
\hline S8 & 1.00 & S8 & 1.00 & 1 \\
\hline S9 & 1.00 & S9 & 1.00 & 0 \\
\hline $\mathrm{S} 10$ & 0.638 & S6, S7, S16, S26 & $0.06,0.06,0.14,1.09$ & 0 \\
\hline $\mathrm{S} 11$ & 0.725 & $\mathrm{~S} 1, \mathrm{~S} 6, \mathrm{~S} 26$ & $0.01,0.03,1.66$ & 0 \\
\hline $\mathrm{S} 12$ & 0.943 & S16, S17 & $1.15,0.29$ & 0 \\
\hline $\mathrm{S} 13$ & 1.00 & $\mathrm{~S} 13$ & 1.00 & 2 \\
\hline $\mathrm{S} 14$ & 0.862 & $\mathrm{~S} 17, \mathrm{~S} 23, \mathrm{~S} 25, \mathrm{~S} 34$ & $0.58,0.12,0.86,0.07$ & 0 \\
\hline $\mathrm{S} 15$ & 1.00 & $\mathrm{~S} 15$ & 1.00 & 0 \\
\hline S16 & 1.00 & S16 & 1.00 & 6 \\
\hline S17 & 1.00 & S17 & 1.00 & 12 \\
\hline $\mathrm{S} 18$ & 0.873 & $\mathrm{~S} 17, \mathrm{~S} 23, \mathrm{~S} 25, \mathrm{~S} 34$ & $0.51,0.04,1.34,0.02$ & 0 \\
\hline S19 & 0.866 & $\mathrm{~S} 13, \mathrm{~S} 17, \mathrm{~S} 26, \mathrm{~S} 34$ & $0.37,0.43,1.80,0.04$ & 0 \\
\hline $\mathrm{S} 20$ & 0.548 & $\mathrm{~S} 17, \mathrm{~S} 25, \mathrm{~S} 26$ & $0.12,0.04,1.43$ & 0 \\
\hline $\mathrm{S} 21$ & 0.626 & $\mathrm{~S} 13, \mathrm{~S} 23, \mathrm{~S} 25, \mathrm{~S} 26, \mathrm{~S} 34$ & $0.14,0.37,0.25,0.61,0.06$ & 0 \\
\hline $\mathrm{S} 22$ & 0.743 & $\mathrm{~S} 17, \mathrm{~S} 23, \mathrm{~S} 25, \mathrm{~S} 34$ & $0.05,0.26,0.79,0.20$ & 0 \\
\hline $\mathrm{S} 23$ & 1.00 & $\mathrm{~S} 23$ & 1.00 & 5 \\
\hline $\mathrm{S} 24$ & 0.499 & $\mathrm{~S} 8, \mathrm{~S} 16, \mathrm{~S} 23, \mathrm{~S} 26$ & $0.25,0.12,0.12,0.52$ & 0 \\
\hline $\mathrm{S} 25$ & 1.00 & $\mathrm{~S} 25$ & 1.00 & 7 \\
\hline S26 & 1.00 & $\mathrm{~S} 26$ & 1.00 & 13 \\
\hline $\mathrm{S} 27$ & 0.599 & S16, S17 & $0.64,0.28$ & 0 \\
\hline $\mathrm{S} 28$ & 0.637 & S6, S16, S26 & $0.35,0.24,0.58$ & 0 \\
\hline $\mathrm{S} 29$ & 0.820 & S17 & 1.17 & 0 \\
\hline $\mathrm{S} 30$ & 0.895 & S6, S16, S26 & $0.14,0.78,0.32$ & 0 \\
\hline $\mathrm{S} 31$ & 0.519 & $\mathrm{~S} 17, \mathrm{~S} 25, \mathrm{~S} 26$ & $0.18,1.00,0.02$ & 0 \\
\hline $\mathrm{S} 32$ & 0.542 & $\mathrm{~S} 17, \mathrm{~S} 26$ & $0.10,1.28$ & 0 \\
\hline S33 & 0.842 & $\mathrm{~S} 17, \mathrm{~S} 26, \mathrm{~S} 34$ & $0.02,1.43,0.31$ & 0 \\
\hline S34 & 1.00 & S34 & 1.00 & 6 \\
\hline S35 & 0.501 & $\mathrm{~S} 17, \mathrm{~S} 25, \mathrm{~S} 26$ & $0.21,0.34,0.51$ & 0 \\
\hline Mean & 0.833 & & & \\
\hline
\end{tabular}

[3] makes it possible to replace (1) with an equivalent linear programming problem by imposing the condition $\sum_{i=1}^{m} v_{i k} x_{i k}=1$ which provides:

$$
\operatorname{Max}_{k}=\sum_{r=1}^{s} u_{r k} y_{r k}
$$


subject to

$$
\begin{array}{ll}
\sum_{i=1}^{m} v_{i k} x_{i k}=1 & \\
\sum_{r=1}^{s} u_{r k} y_{r j}-\sum_{i=1}^{m} v_{i k} x_{i j} \leq 0 & \forall j=1,2, \ldots, n \\
u_{r k} \geq \varepsilon & \forall r=1,2, \ldots, s \\
v_{i k} \geq \varepsilon & \forall i=1,2, \ldots, m
\end{array}
$$

Model (2) is interpreted that the objective is to maximize virtual output of $\mathrm{DMU}_{k}$ subject to unit virtual input of $\mathrm{DMU}_{k}$ while maintaining the condition that virtual output cannot exceed virtual input for every DMU. This is known as CCR multiplier model whose dual LPP is

$$
\text { Min } z_{k}=\theta_{k}-\varepsilon \sum_{r=1}^{s} S_{r k}^{+}-\varepsilon \sum_{i=1}^{m} S_{i k}^{-}
$$

subject to

$$
\begin{array}{lr}
\sum_{j=1}^{n} \lambda_{j k} y_{r j}-S_{r k}^{+}=y_{r k} & \forall r=1 \ldots \ldots . . s \\
\sum_{j=1}^{n} \lambda_{j k} x_{i j}+S_{i k}^{-}=\theta_{k} x_{i k} & \forall i=1 \ldots \ldots \ldots m \\
\lambda_{j k} \geq 0 & \forall j=1 \ldots \ldots \ldots n \\
\theta_{k} \text { is unrestricted in sign } & \\
S_{r k}^{+}, S_{i k}^{-} \geq 0 ; r=1 \ldots . . ., i=1 \ldots . . m &
\end{array}
$$

where $S_{r k}^{+}$is slack in the $\mathrm{r}^{\text {th }}$ output of the $\mathrm{k}^{\text {th }} \mathrm{DMU} ; S_{i k}^{-}$is slack in the $\mathrm{i}^{\text {th }}$ input of the $\mathrm{k}^{\text {th }} \mathrm{DMU} ; \lambda_{j k}{ }^{\prime} s$ are non negative dual variables and $\theta_{k}$ (scalar) is the (proportional) reduction applied to all inputs of $\mathrm{DMU}_{k}$ to improve efficiency. This reduction is applied simultaneously to all inputs and results in a radial movement towards the envelopment surface. This is popularly known as CCR envelopment model.

The interpretation of the results of the envelopment model (3) can be summarized as:

The $\mathrm{k}^{\text {th }} \mathrm{STU}$ is Pareto efficient if

(a) $\theta_{k}^{*}=1$

(b) All slacks are zero, i.e., $S_{r k}^{+*}$ and $S_{i k}^{-*}=0$ for every $\mathrm{r}$ and $\mathrm{i}$.

The non-zero slacks and (or) $\theta_{k}^{*} \leq 1$ identify the sources and amount of any inefficiency that may exist in the $\mathrm{DMU}_{k}$. If the optimal value $\lambda_{j k}^{*}$ of $\lambda_{j k}$ is non zero then $\mathrm{j}^{\text {th }}$ DMU represents the reference set (peers) of the $\mathrm{k}^{\text {th }}$ DMU.

Fifth Step: Calculate OTE of every sample STU. The detailed information of the results is given in Table 2

Sixth Step: Calculating the pure technical efficiency (PTE) and scale efficiency (SE) of STU: Another version of DEA is BCC model given by Banker, Charnes and Cooper [1]. The primary difference between BCC model and CCR model is 
the convexity constraint, which represents the returns to scale. Returns to scale reflects the extent to which a proportional increase in all inputs increases outputs. In the BCC model $\lambda_{j k}$ 's are now restricted to $\sum_{j=1}^{n} \lambda_{j k}=1$ which is known as convexity constraint. Technical efficiency assessed by BCC model is pure technical efficiency because it has net of any scale effect. The impact of scale-size on efficiency of a DMU is measured by scale efficiency.

$$
\begin{aligned}
\text { Scale Efficiency of the } k^{\text {th }} D M U & =\frac{\text { Overall Technical Efficiency of the } k^{\text {th }} D M U}{\text { Pure Technical Efficiency of the } k^{\text {th }} D M U} \\
& =\frac{\text { CCR Efficiency Score of the } k^{\text {th }} D M U}{\text { BCC Efficiency Score of the } k^{\text {th }} D M U}
\end{aligned}
$$

The overall technical efficiency (OTE) of a DMU can never exceed its pure technical efficiency (PTE). All the three efficiencies (overall technical, pure technical and scale) are bounded by zero and one.

Seventh Step: Calculate PTE and SE of every sample STU. The detailed information of DEA results is given in Table 5.

\section{Empirical results and discussions}

Table 2 presents the information on OTE, reference set, peer weights and reference count (peer count) of the sample STUs for the year 2004-05. The DEA analysis evaluates the set of STUs which construct the production frontier. The STUs having values of the OTE score equal to 1.00 are form the efficient frontier and those having the values less than 1.00 are less efficient relative to the STUs on the frontier. The lower the efficiency score, the higher scope for the potential reduction in inputs (while maintaining the existing level of outputs) relative to the best practice STUs.

The results indicate that out of 35 STUs, 14 STUs (40\%) are relatively efficient (efficiency score $=1$ ) while remaining 21 STUS are relatively inefficient (efficiency score $<1$ ). These fourteen efficient STUs are APSRTC (S1), RSRTC (S5), KnSRTC (S6), NWKnSRTC (S7), NSKnSRTC (S8), STHAR (S9), KUM-1 (S13), MDU (S15), SLM (S16), VPM-1 (S17), OSRTC (S23), TRPTC (S25), MZST (S26), and KMTU (S34). These STUs are on the best-practice frontier and thus form the "reference set", i.e., these STUs can set an example of good operating practice for the remaining 21 inefficient STUs to emulate. HRTC (S24) is the most technical inefficient STU. Among the inefficient STUs, 7 STUs have the efficiency scores above the average efficiency scores.

The average of OTE scores works out to be 0.833 . This reveals that an average STU can reduce its resources by $16.74 \%$ to obtain the existing level of outputs.

We use the frequency of efficient STUs in the reference set (i.e., peer count) to discriminate among them. The higher peer count represents the extent of robustness of that STU compared with other efficient STUs. In other words, a STU with higher peer count is likely to be a STU which is efficient with respect to a large number of factors and is probably a good example of a "global leader" or a STU with a high 
robustness. Efficient STUs that appear seldom in the reference set are likely to possess a very uncommon input/output mix so when the peer count is low, one can safely conclude that the STU is somewhat of an odd unit and cannot be treated as a good example to be followed. On the basis of robustness of efficiency scores, the STUs on the frontier are classified as:

1. High robustness: MZST (S26, peer count =13) and VPM-1 (S17, peer count $=12)$ are high robust STU and can be considered as global leaders in terms of OTE.

2. Middle robustness: APSRTC (S1), KnSRTC (S6), SLM (S16), OSRTC (S23), TRPTC (S25) and KMTU (S34) are classified in the middle robust group.

3. Low robustness: RSRTC (S5), NWKnSRTC (S7), NSKnSRTC (S8), STHAR (S9), KUM-1 (S13) and MDU (S15) are graded in the low robust group in terms of OTE.

\subsection{Input/Output targets for inefficient STUs}

When a STU is inefficient, DEA allows to set the targets for its inputs and outputs so that it can improve its performance. Thus, each of the inefficient STU can become overall efficient by adjusting its operation to the associated target point determined by the efficient STUs that define its reference frontier. According to model, the targets of the inefficient STUs are as follows:

For outputs :

For inputs :

$$
\overline{y_{r k}}=y_{r k}+S_{r k}^{+*}=\sum_{j=1}^{n} \lambda_{j k}^{*} y_{r j}
$$

$$
\overline{x_{i k}}=\theta_{k}^{*} x_{i k}-S_{i k}^{-*}=\sum_{j=1}^{n} \lambda_{j k}^{*} x_{i j}
$$

where $\overline{y_{r k}}(r=1,2,3)$ and $\overline{x_{i k}}(i=1,2,3,4)$ are the target outputs and inputs respectively for the $\mathrm{k}^{\text {th }} \mathrm{STU} ; y_{r k}$ and $x_{i k}$ are the actual outputs and inputs respectively of the $\mathrm{k}^{\text {th }} \mathrm{STU} ; \theta_{k}^{*}=$ optimal efficiency score of the $\mathrm{k}^{\text {th }} \mathrm{STU} ; S_{i k}^{-{ }^{*}}$ is the optimal input slack of the $\mathrm{k}^{\text {th }} \mathrm{STU}$ for $\mathrm{i}=1 \ldots 4$; and $S_{r k}^{+^{*}}$ is the optimal output slack of the $\mathrm{k}^{\text {th }}$ STU for $r=1 \ldots 3$. The optimal input and output slacks for every inefficient STU are shown in Table 3.

Table 4 presents the target values of all inputs and outputs for inefficient STUs along with percentage reduction in inputs and percentage expansion in outputs. It can be observed from the table that an average STU has a significant scope to reduce the inputs and expand the outputs, relative to the best practice STU. A perusal of the Table, it can be observed that on average, approximately $30 \%$ of FS, $37.75 \%$ of TS, 23.93 of FC, $41.24 \%$ of APLK can be reduced and $19.34 \%$ of BU, $26.14 \%$ of LF can be expanded if all the inefficient STUs operate at the level of efficient STUs. The results reveal that in order to become efficient, the worst inefficient STU, i.e., HRTC (S24, TE score $=49.94 \%$ ), can reduce its FS by $51.18 \%$, TS, FC, APLK by $50.06 \%$, and expand LF by $11.09 \%$ relative to the best practice STU. 
Table 3 Slacks in inputs/outputs

\begin{tabular}{|c|c|c|c|c|c|c|c|c|}
\hline \multirow[t]{2}{*}{ STU No } & \multirow[t]{2}{*}{ STU Name } & \multicolumn{4}{|l|}{ Inputs } & \multicolumn{3}{|l|}{ Outputs } \\
\hline & & FS & TS & $\mathrm{FC}$ & APLK & $\mathrm{BU}$ & Pass Kms & LF \\
\hline S2 & MSRTC & 0 & 6.02 & 1 & 0 & 123.82 & 0 & 31.54 \\
\hline S3 & GSRTC & 0 & 5.9 & 0.21 & 0 & 22.82 & 0 & 5.17 \\
\hline S4 & UPSRTC & 4.13 & 3.49 & 0 & 0 & 0 & 0 & 1.18 \\
\hline $\mathrm{S} 10$ & STPJB & 2.4 & 1.01 & 0 & 0 & 0 & 0 & 0 \\
\hline S11 & BSRTC & 0.44 & 0.55 & 0 & 0 & 7.43 & 0 & 0 \\
\hline $\mathrm{S} 12$ & $\mathrm{CBE}$ & 1.46 & 0.63 & 0 & 0 & 248.51 & 0 & 32.98 \\
\hline S14 & KUM-2 & 0.44 & 0 & 0 & 0 & 0 & 0 & 49.91 \\
\hline S18 & VPM-3 & 0.21 & 0 & 0 & 0 & 0 & 0 & 69.46 \\
\hline S19 & $\mathrm{TN}$ & 0 & 0 & 0.91 & 0 & 0 & 0 & 56.95 \\
\hline S20 & NBSTC & 0.66 & 0.98 & 0 & 0.09 & 0 & 0 & 0 \\
\hline S21 & SBSTC & 0 & 0 & 0 & 0 & 0 & 0 & 27.59 \\
\hline S22 & KDTC & 0.52 & 0 & 0 & 0 & 0 & 0 & 42.24 \\
\hline S24 & HRTC & 0.19 & 0 & 0 & 0 & 0 & 0 & 5.49 \\
\hline S27 & BEST & 5.55 & 12.52 & 0 & 0 & 210.8 & 0 & 8.46 \\
\hline S28 & DTC & 0.02 & 6.77 & 0 & 0 & 78.4 & 0 & 0 \\
\hline S29 & $\mathrm{CNI}$ & 5.8 & 6.76 & 0 & 0.09 & 305.6 & 0 & 15.85 \\
\hline S30 & BMTC & 13.5 & 3.84 & 0 & 0 & 208.08 & 0 & 0 \\
\hline S31 & CSTC & 1.23 & 2.02 & 0 & 0.02 & 0 & 0 & 0 \\
\hline S32 & AMTS & 0.66 & 0.4 & 0 & 0.38 & 0 & 0 & 3.11 \\
\hline S33 & PCMT & 0 & 0 & 0.03 & 0.06 & 0 & 0 & 9.14 \\
\hline S35 & PMT & 1.28 & 1.26 & 0 & 0.11 & 0 & 0 & 0 \\
\hline Mean & & 1.83 & 2.48 & 0.10 & 0.036 & 57.40 & 0 & 17.10 \\
\hline
\end{tabular}

\subsection{Pure technical efficiency}

CCR model is based on the assumption of constant returns to scale (CRS) which does not consider the scale-size of STU to be relevant in assessing technical efficiency. Therefore, in order to know whether inefficiency in any STU is due to inefficient production operation or due to unfavorable conditions displayed by the size of STU, BCC input model is also applied.

BCC efficiency (PTE) is always greater or equal to CCR efficiency (OTE). Hence, number of STUs on the frontier under BCC model is always greater or equal to the number of STUs on the frontier under CCR model.

Table 5 provides details about DEA results drawn from this model. It is evident from the Table that out of 35 STUs, 18 STUs are pure technical efficient $(\mathrm{BCC}$ score $=1$ ), i.e., none of these have scope to further reduce inputs (maintaining same output level) while remaining 17 STUs are relatively inefficient (score $<1$ ). PTE measures how efficiently inputs are converted into output(s) irrespective of the size of the STUs. The average of pure technical efficiency is worked out to be 0.875 ; this means that given the scale of 


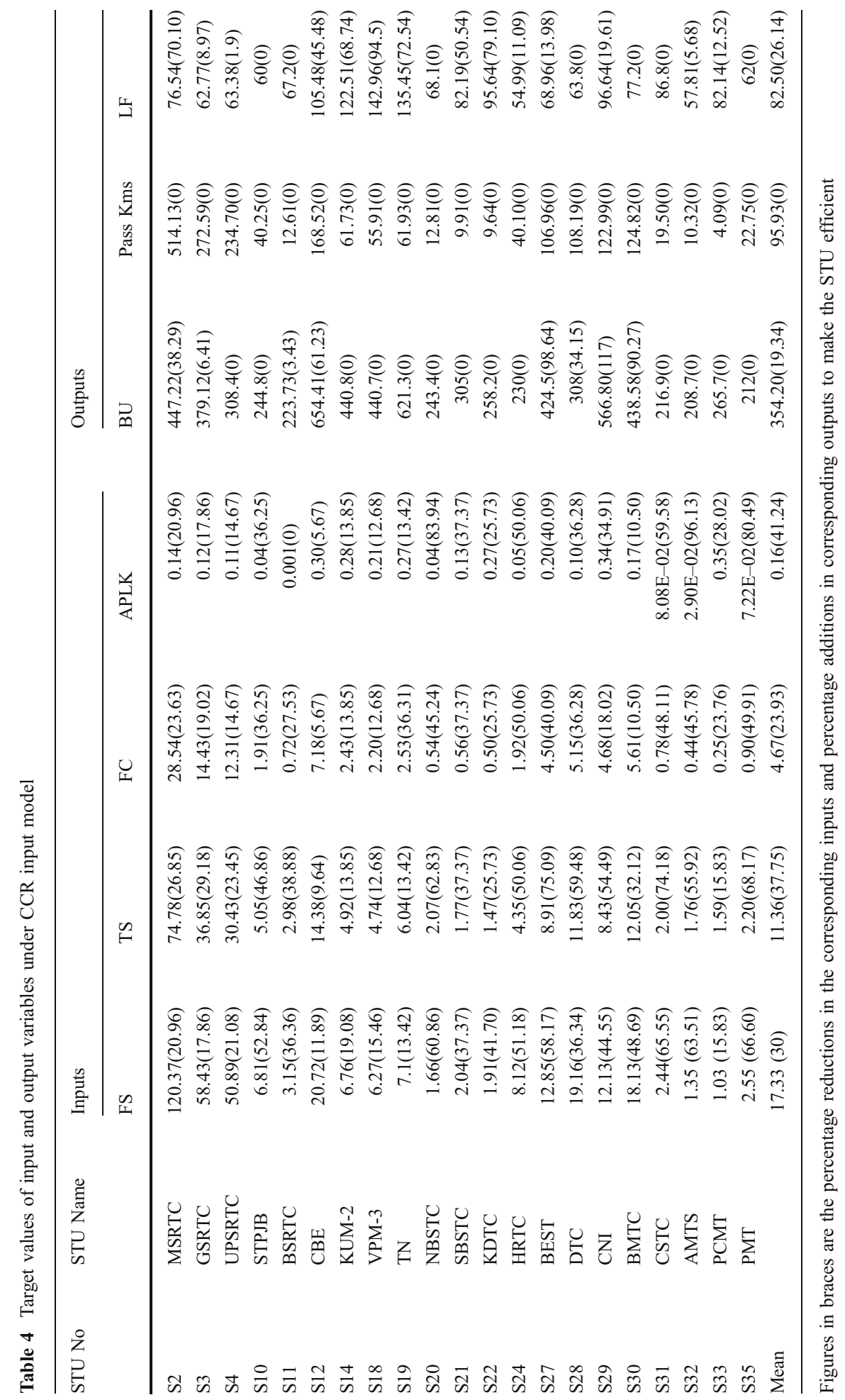


Table 5 OTE, PTE and SE

\begin{tabular}{llll}
\hline STU No. & $\begin{array}{l}\text { Overall technical } \\
\text { efficiency }\end{array}$ & $\begin{array}{l}\text { Pure technical } \\
\text { efficiency }\end{array}$ & Scale efficiency \\
\hline
\end{tabular}

\begin{tabular}{|c|c|c|c|}
\hline $\mathrm{S} 1$ & 1.00 & 1.00 & 1.00 \\
\hline $\mathrm{S} 2$ & 0.790 & 0.797 & 0.992 \\
\hline $\mathrm{S} 3$ & 0.821 & 0.821 & 1.00 \\
\hline S4 & 0.853 & 0.855 & 0.998 \\
\hline S5 & 1.00 & 1.00 & 1.00 \\
\hline S6 & 1.00 & 1.00 & 1.00 \\
\hline S7 & 1.00 & 1.00 & 1.00 \\
\hline S8 & 1.00 & 1.00 & 1.00 \\
\hline S9 & 1.00 & 1.00 & 1.00 \\
\hline S10 & 0.638 & 0.668 & 0.955 \\
\hline S11 & 0.725 & 1.00 & 0.725 \\
\hline S12 & 0.943 & 0.954 & 0.988 \\
\hline S13 & 1.00 & 1.00 & 1.00 \\
\hline S14 & 0.862 & 0.884 & 0.975 \\
\hline S15 & 1.00 & 1.00 & 1.00 \\
\hline S16 & 1.00 & 1.00 & 1.00 \\
\hline S17 & 1.00 & 1.00 & 1.00 \\
\hline S18 & 0.873 & 0.917 & 0.952 \\
\hline S19 & 0.866 & 1.00 & 0.866 \\
\hline S20 & 0.548 & 0.618 & 0.886 \\
\hline S21 & 0.626 & 0.696 & 0.899 \\
\hline S22 & 0.743 & 0.788 & 0.943 \\
\hline $\mathrm{S} 23$ & 1.00 & 1.00 & 1.00 \\
\hline S24 & 0.499 & 0.499 & 0.999 \\
\hline S25 & 1.00 & 1.00 & 1.00 \\
\hline S26 & 1.00 & 1.00 & 1.00 \\
\hline S27 & 0.599 & 0.599 & 0.999 \\
\hline S28 & 0.637 & 0.641 & 0.994 \\
\hline S29 & 0.820 & 0.861 & 0.952 \\
\hline S30 & 0.895 & 0.923 & 0.970 \\
\hline S31 & 0.519 & 1.00 & 0.519 \\
\hline S32 & 0.542 & 0.583 & 0.930 \\
\hline S33 & 0.842 & 1.00 & 0.842 \\
\hline S34 & 1.00 & 1.00 & 1.00 \\
\hline S35 & 0.501 & 0.504 & 0.994 \\
\hline Mean & 0.833 & 0.875 & 0.953 \\
\hline
\end{tabular}

operation, on average, STUs can reduce its inputs by $12.5 \%$ of its observed level without detriment to its output levels.

Pure technical efficiency is concerned with the efficiency in converting inputs to outputs for the given the scale-size of STUs, whereby we observe that S11, S19, S31 and S33 are CCR technical inefficient but pure technical efficient. This clearly 
evinces that these STUs are able to convert its inputs into outputs with $100 \%$ efficiency, but their overall efficiency (OTE) is low due to their scale-size disadvantageous (low scale efficiency).

\subsubsection{Scale efficiency (SE)}

A comparison of the results for $\mathrm{CCR}$ and $\mathrm{BCC}$ gives an assessment of whether the size of a STU has an influence on its OTE. Scale efficiency (SE) is the ratio of OTE to PTE scores. If the value of SE score is one, then the STU is apparently operating at optimal scale. If the value is less than one, then the STU appears either small or big relative to its optimum scale-size. Table 5 represents the SE score of the STUs at fourth column. Results show that out of 35 STUs, 15 STUs are scale efficient while remaining 20 STUs are scale inefficient. The average of scale efficiency is 0.953 . It indicates that an average STU may be able to decrease its inputs by $4.7 \%$ beyond its best practice targets under variable returns to scale, if it were to operate at constant returns to scale.

\section{Conclusions and policy implementations}

This paper measures technical efficiency (OTE) of 35 STUs in India through DEA methodology. The study finds that 14 STUs have the maximum degree of efficiency. The overall mean TE of the STUs is $83.26 \%$, indicating that on average $16.74 \%$ of the technical potential of the STUs is not in use. This implies that these STUs have the scope of producing the same output with the inputs $16.74 \%$ lesser than their existing level. The most efficient STUs are MZST and VPM-1 while HRTC is the most inefficient STU.

The targets setting results show that all the inputs have the significant scope to reduce. The model suggests that on average, non-frontier STUs may be able to reduce Fleet Size by $30 \%$, Total Staff by $37.75 \%$, Fuel Consumption by $2.93 \%$, APKL by $41.24 \%$, and to expand BU by $19.34 \%$, LF by $26.14 \%$, relative to the best practice STUs.

The results of BCC model show that out of 35 STUs, 18 STUs are pure technical efficient as they efficiently convert their inputs into the output. However, 4 STUs of them are technical inefficient due to scale-size effect. S31 has the least scale efficiency score (51.9\%), implying that S31 has the maximum effect of scale-size on its efficiency score.

\section{Appendix A.1}

STUs selected for the study are as follows:

\begin{tabular}{|c|c|c|c|c|}
\hline $\begin{array}{l}\text { STU } \\
\text { No. }\end{array}$ & $\begin{array}{l}\text { STU } \\
\text { acronym }\end{array}$ & STU name & State of operation & Nature of organization \\
\hline S1 & APSRTC & $\begin{array}{l}\text { Andhra Pradesh State Road } \\
\text { Transport Corporation }\end{array}$ & Andhra Pradeshation & Corporation \\
\hline $\mathrm{S} 2$ & MSRTC & $\begin{array}{l}\text { Maharashtra State Road } \\
\text { Transport Corporation }\end{array}$ & Maharashtra & Corporation \\
\hline S3 & GSRTC & $\begin{array}{l}\text { Gujarat State Road Transport } \\
\text { Corporation }\end{array}$ & Gujarat & Corporation \\
\hline
\end{tabular}


(continued)

\begin{tabular}{|c|c|c|c|c|}
\hline $\begin{array}{l}\text { STU } \\
\text { No. }\end{array}$ & $\begin{array}{l}\text { STU } \\
\text { acronym }\end{array}$ & STU name & State of operation & Nature of organization \\
\hline S4 & UPSRTC & $\begin{array}{l}\text { Uttar Pradesh State Road } \\
\text { Transport Corporation }\end{array}$ & Uttar Pradesh & Corporation \\
\hline S5 & RSRTC & $\begin{array}{l}\text { Rajasthan State Road } \\
\text { Transport Corporation }\end{array}$ & Rajasthan & Corporation \\
\hline S6 & KnSRTC & $\begin{array}{l}\text { Karnataka State Road } \\
\text { Transport Corporation }\end{array}$ & Karnataka & Corporation \\
\hline S7 & NWKnSRTC & $\begin{array}{l}\text { North West Karnataka State } \\
\text { Road Transport Corporation }\end{array}$ & Karnataka & Corporation \\
\hline S8 & NSKnSRTC & $\begin{array}{l}\text { North South Karnataka State } \\
\text { Road Transport Corporation }\end{array}$ & Karnataka & Corporation \\
\hline S9 & STHAR & State Transport Haryana & Haryana & Government Deptt. \\
\hline $\mathrm{S} 10$ & STPJB & State Transport Punjab & Punjab & Government Deptt \\
\hline S11 & BSRTC & $\begin{array}{l}\text { Bihar State Road Transport } \\
\text { Corporation }\end{array}$ & Bihar & Corporation \\
\hline S12 & CBE-1 & Coimbatore Division & Tamil Nadu & Company \\
\hline S13 & KUM-1 & Kumbakonam Division 1 & Tamil Nadu & Company \\
\hline S14 & KUM-2 & Kumbakonam Division 2 & Tamil Nadu & Company \\
\hline S15 & MDU & Madurai Division & Tamil Nadu & Company \\
\hline S16 & SLM & Salem Division & Tamil Nadu & Company \\
\hline S17 & VPM-1 & Villuparam Division 1 & Tamil Nadu & Company \\
\hline S18 & VPM-3 & Villuparam Division 3 & Tamil Nadu & Company \\
\hline S19 & $\mathrm{TN}$ & $\begin{array}{l}\text { Tamil Nadu State Express } \\
\text { Transport Corporation Limited }\end{array}$ & Tamil Nadu & Company \\
\hline S20 & NBSTC & $\begin{array}{l}\text { North Bengal State Road } \\
\text { Transport Corporation }\end{array}$ & West Bengal & Corporation \\
\hline $\mathrm{S} 21$ & SBSTC & $\begin{array}{l}\text { South Bengal State Road } \\
\text { Transport Corporation }\end{array}$ & West Bengal & Corporation \\
\hline S22 & KDTC & $\begin{array}{l}\text { Kadamba Transport } \\
\text { Corporation Limited }\end{array}$ & Goa & Company \\
\hline $\mathrm{S} 23$ & OSRTC & $\begin{array}{l}\text { Orissa State Road Transport } \\
\text { Corporation }\end{array}$ & Orissa & Corporation \\
\hline $\mathrm{S} 24$ & HRTC & $\begin{array}{l}\text { Himachal Road Transport } \\
\text { Corporation }\end{array}$ & Himachal Pradesh & Corporation \\
\hline $\mathrm{S} 25$ & TRPTC & $\begin{array}{l}\text { Tripura Road Transport } \\
\text { Corporation }\end{array}$ & Tripura & Corporation \\
\hline S26 & MZST & Mizoram State Transport & Mizoram & Government Deptt. \\
\hline S27 & BEST & $\begin{array}{l}\text { Brihan Mumbai Electric Supply } \\
\text { \& Transport Undertaking }\end{array}$ & Mumbai city & Municipal Undertakings \\
\hline S28 & DTC & Delhi Transport Corporation & Delhi & Corporation \\
\hline S29 & $\mathrm{CNI}$ & $\begin{array}{l}\text { Chennai Metropolitan Transport } \\
\text { Corporation Limited }\end{array}$ & Chennai city & Company \\
\hline S30 & BMTC & $\begin{array}{c}\text { Bangalore Metropolitian } \\
\text { Transport Corporation }\end{array}$ & Bangalore city & Corporation \\
\hline S31 & CSTC & $\begin{array}{l}\text { Calcutta State Transport } \\
\text { Corporation }\end{array}$ & Kolkatta city & Corporation \\
\hline S32 & AMTS & $\begin{array}{l}\text { Ahmedabad Municipal } \\
\text { Transport Service }\end{array}$ & Ahmedabad city & Municipal Undertakings \\
\hline
\end{tabular}


(continued)

\begin{tabular}{lllll}
\hline $\begin{array}{l}\text { STU } \\
\text { No. }\end{array}$ & $\begin{array}{l}\text { STU } \\
\text { acronym }\end{array}$ & STU name & State of operation & Nature of organization \\
\hline S33 & PCMT & $\begin{array}{c}\text { Pimpri Chinchwad } \\
\text { Municipal Transport }\end{array}$ & Pune city & Municipal Undertakings \\
S34 & KMTU & $\begin{array}{c}\text { Kohlapur Municipal } \\
\text { Transport Undertakings } \\
\text { Pune Municipal Transport }\end{array}$ & Kohlapur city & Municipal Undertakings \\
S35 & PMT & & Pune city & Municipal Undertakings \\
\hline
\end{tabular}

\section{References}

1. Banker, R.D., Charnes, A., Cooper, W.W.: Some Models for the Estimation of Technical and Scale Inefficiencies in Data Envelopment Analysis. Manage Sci 30, 1078-1092 (1984)

2. Charnes, A., Cooper, W.W., Rhodes, E.: Measuring the Efficiency of Decision Making Units. Eur J Oper Res 2, 429-441 (1978)

3. Charnes, A., Cooper, W.W.: Programming with Linear Fractional Functional. Nav Res Logistics Q 9 , 181-186 (1962)

4. Charnes, A., Cooper, W.W., Lewin, A.Y., Seiford, L.M.: Data Envelopment Analysis: Theory Methodology and Application, Kluwer, Massachusetts (1997)

5. CIRT, Pune: "Indian Journal of Transport Management", 29. Available on www.asrtu.org \scan0012.pdf accessed on 15 March 2006. (2005) 